\title{
ENTRE IDENTIDADE E SUBJETIVIDADE: UMA REFLEXÃO A PARTIR DOS RELATOS DE SUJEITOS COM AUTISMO
}

\author{
Ricardo Falbo ${ }^{1}$ \\ Attila Secchin ${ }^{2}$
}

\begin{abstract}
Resumo:
Universal por estar no direito e particular por estar fora do direito, o "sujeito" de referência deste trabalho é o "autista". Esta escolha garantiu a definição do sistema social, que foi concebido segundo o modo como os autistas se viam ou eram vistos. O sistema teórico foi delimitado segundo tradições intelectuais que problematizam o "sujeito" de acordo com questões formuladas pelos campos empíricos. $\mathrm{O}$ esquema metodológico visa a conhecer o "sujeito" por dentro dos sistemas e entre eles. O objetivo teórico é pensar o "sujeito" considerando que o universal do direito não resulta da pluralidade do "sujeito".
\end{abstract}

Palavras-chave: Sujeito Empírico; Direito Universal; Ser Autista; Teoria do Sujeito; Teoria do Direito

\section{BETWEEN IDENTITY AND SUBJECTIVITY: A REFLECTION FROM THE ACCOUNTS OF SUBJECTS WITH AUTISM}

\begin{abstract}
:
Universal because inside law and particular because outside law, "autistic people" are the subject matter in this work. They stand for social system, which was defined by the way autistic people see themselves and are seen. Theoretical system according to intellectual traditions on problems concerning "the subject" on empirical observations. Methodological research scheme aims to recognize the existence of "the subject" within and between systems. Theoretical objective is to think over "the subject" considering the universal dimension of law does not result from the plurality of "the subject".
\end{abstract}

Keywords: Empirical Subject; Universal Law; To Be Autistic; Theory of Subject; Theory of Law

\section{INTRODUÇÃO}

"O direito ocidental é o lugar próprio (...) da emergência e da autoridade do sujeito, do conceito de sujeito. Se ele está mantido no direito, está por toda a parte. Como

\footnotetext{
${ }^{1}$ Pós-doutorado em sociologia urbana pela Université Paris 2. Professor de Sociologia Jurídica na Graduação e de Epistemologia das Ciências Sociais na pós-graduação da Faculdade de Direito da Universidade do Estado do Rio de Janeiro.

${ }^{2}$ Mestre em Teoria e Filosofia do Direito pela UERJ. LLM pela Universidade de Harvard. Bacharel em Direito pela Faculdade de Direito de Vitória.
} 
extirparíamos o sujeito do direito?” (DERRIDA, ROUDINESCO, 2004, p. 74). Esta citação dos autores de De que amanhã... permite pensar o caráter universal do "sujeito" que está em toda a parte no mundo como referência à universalidade do direito ocidental. Como lugar privilegiado do direito universal, a lei é também o lugar comum do "sujeito". Por outro lado, "mantido no direito", o "sujeito" pode ser definido como categoria tanto "prática" (na sua "emergência" e "autoridade") como teórica (na sua "conceituação"). Assim, o caráter universal da relação que articula estas duas dimensões permite pensar o "sujeito" sem predicado outro que não a própria universalidade. É o "sujeito-forma". É o "sujeito-estrutura". No entanto, considerando que, "por toda a parte" em que se encontra, o "sujeito" existe determinado e se determina por significações distintas e diversas como função das formas particulares de interação com outros "sujeitos" que existem em outros "lugares" que não o próprio direito, é possível, então, reconhecer que o sujeito passa a existir de forma qualificada. É o "sujeito-conteúdo". É o "sujeito-contingência”. Neste trabalho, a parte em que está o sujeito - universal ou particular - será denominada de "sistema" ou "campo". Ela será abordada como expressão de "fenomenologias", que, quanto a dimensões tanto práticas quanto teóricas, caracterizam-se não por “essencialidades" próprias, e sim por revelarem instâncias que são definidas por sistemas classificatórios particulares, ainda que elas se pensem e/ou se afirmem como sendo "universais" ou "universalisáveis".

Universal por estar no direito - ainda que definido de forma particular - e particular por estar fora do direito - ainda que contemplado por vezes de forma universal -, o "sujeito" objeto de referência neste trabalho de caráter exploratório é o "sujeito autista". Em razão da amplitude tanto do "sujeito no direito" como do "direito do sujeito", a determinação "empírica" ou "prática" de ambos procura atender à necessidade de identificar e escolher os "elementos" que possam expressar e garantir a discussão quanto a "o que" é o "direito" e quanto a "quem" é o "sujeito" referentemente às diversas "fenomenologias". Assim, a escolha do direito determinou a escolha do sujeito. O direito escolhido representa a lei brasileira que consagra a "Política Nacional de Proteção dos Direitos da Pessoa com Transtorno do Espectro Autista". ${ }^{3}$ Esta escolha garantiu a definição de dois campos ou sistemas de investigação do “sujeito" em sua dimensão "prática" ou "empírica". Primeiro: o sistema social, definido pelo campo das relações dos autistas. Segundo: o sistema jurídico, definido pelo campo das

\footnotetext{
${ }^{3}$ Promulgada em 2012, a lei 12.764 consagra direitos que têm fundamento em outras normas e leis. Esta foi a razão de sua escolha.
} 
normas. A complexidade destes dois campos determinou a ausência do sistema médico deste trabalho como campo "empírico" dos diagnósticos. Quanto a este campo, trabalhar-se-á de forma operacional com a seguinte compreensão de autismo: "[termo] guarda-chuva, abrangendo um intervalo enorme de pacientes, variando amplamente em habilidades cognitivas e sociais, bem como condições genéticas ou neurológicas associadas" (BAKER, 2013, p. 1090, tradução nossa). Definido pelo campo das definições de natureza "teórica", o sistema de pensamento foi delimitado segundo tradições intelectuais que problematizam o "sujeito" de acordo com questões semelhantes àquelas formuladas pelos demais sistemas ou campos empíricos.

O campo social foi definido segundo a realização de entrevistas - diretas ou indiretas - com autistas e/ou com seus familiares; o campo jurídico, pelas regras em vigor no Brasil quanto à proteção dos direitos do autista enquanto pessoa. O sistema de pensamento, pela diversidade de perspectivas, interesses e objetivos de seus autores quanto ao tema "sujeito". Este plano de investigação possui como objetivo, através da comparação entre os diversos sistemas, reconhecer não o caráter tópico da linguagem "sujeito" nestes sistemas, e sim a existência de perspectivas ou pontos de vista específicos e diversos sob os quais o "sujeito" existe, se manifesta e é concebido por dentro dos sistemas e entre eles. Do ponto de vista metodológico, o modo de proceder neste trabalho, segundo descrições e explicações da categoria "sujeito" quanto à universalidade que iguala desiguais e quanto à particularidade que desiguala iguais, possui como principal objetivo questionar a determinação recíproca e mútua entre os diversos sistemas de investigação, bem como a existência de metainterpretação ou meta-conceito capaz de instaurar definição universal de "sujeito" capaz de entrar e sair dos diversos campos com sua "identidade" imaculada. Com base na construção de generalizações específicas, os diversos sistemas procedem até mesmo como se eles ou se anulassem de forma recíproca ou se compatibilizassem de forma geral. Do ponto de vista epistemológico, essa problemática desautoriza seja a relação entre as categorias práticas e teóricas para pensar o "sujeito" definida como "relação de subsunção".

Este quadro teórico-metodológico quanto à abordagem das diversas "fenomenologias" referidas ao "sujeito" constitui condição fundamental de formulação de problema de pesquisa e de definição de uma "teoria do sujeito" no Direito. Este é o objetivo de natureza substantiva ou teórica que justifica a importância deste tipo de investigação do 
direito pelo Direito: pensar uma hipótese teórica sobre o "sujeito do direito" com base no pressuposto segundo o qual o universal do direito não resulta da pluralidade do sujeito.

\section{IDENTIDADE, SUJEITO E SISTEMA SOCIAL}

"A gente precisa adivinhar muita coisa. Demorei muito a entender o que era, porque ele não conseguia me explicar. Tivemos que fazer uma microcirurgia no dente, com anestesia geral." "Este é o relato da mãe de Joab, de 22 anos de idade, que narra as dificuldades de conviver com um filho autista que não fala, que sente dor, que não consegue explicar sua dor, que é completamente sedado e que sofre intervenção cirúrgica para que seja eliminada a causa de sua dor. O convívio com um autista sem funcionamento verbal, mesmo para um parente imediato, define o problema do tempo quanto ao diagnóstico de um problema de saúde. Eis aqui um sujeito que não fala e que depende da fala de outro sujeito para que seus problemas sejam conhecidos e tratados.

No entanto, enquanto sujeito que fala e que possui qualidades do sujeito de ação, o autista revela problemas de outra ordem. "Aí, uma vez ele, ele começou a comprar uma van (...) e falou assim: 'mamãe, me dá seu cartão de crédito'. (...) é pra eu fechar uma compra'”. 5 Neste relato, João, de 16 anos de idade - com autismo de maior funcionamento verbal - revela possuir algum grau de consciência e de vontade, algum nível de memória e de conhecimento do mundo. Ele tem acesso ao computador da família e capacidade de usar a internet. Ele quer realizar uma relação de compra e venda on line. Ele sabe onde e como efetuar esta operação. Ele sabe que precisa de um meio de pagamento que ele não possui e sabe a quem recorrer para obtê-lo. O temor da mãe revela a capacidade do filho. João é capaz de memorizar todos os dados necessários para efetuar compras pela internet. Afinal, uma compra realizada importaria a realização de outras compras, passadas ou futuras. Assim, enquanto sujeito que fala e que age, João depende da vigilância e do controle a serem exercidos por outros sujeitos.

"Eu acho também que tá faltando muito dos pais que têm filho (...) saber ensinar respeitar o direito das outras pessoas. (...). Hoje, a pessoa fala 'é doido', as pessoas acham

\footnotetext{
${ }^{4}$ BANDEIRA, Gabriela. Autismo não verbal: mães explicam como é comunicação com filhos adultos. Disponível em: <http://www.portalsingularidades.com.br/2018/02/22/autismo-nao-verbal/>. Acesso em: 03 mar. 2019, 13:45:00.

5 "João", "Leonardo" e "Priscila" são nomes fictícios usados para preservar a identidade das pessoas entrevistadas. Suas falas foram extraídas de entrevistas realizadas pelos autores deste trabalho durante pesquisa exploratória.
} 
graça. (...) Normalmente, o autista é chamado disso, de doido, retardado". De acordo com este relato, o outro com quem o autista se relaciona adota comportamento considerado desrespeitoso por sua mãe. Afinal, o autista é desqualificado como sendo "normal" e definido por seus colegas como sendo "retardado" em razão de sua diferença de comportamento na escola. A mãe do autista identificado como sendo "doido" reconhece que o desrespeito para com o seu filho decorre da falta de educação dos pais que negligenciam simplesmente a lição segundo a qual o "outro" - enquanto pessoa - possui direitos. Assim, a violação do direito da pessoa está associada à identidade que é atribuída à pessoa, isto é, à negação do "outro" como pessoa. "Eu sempre (...) ando com o Leonardo (...) com a blusa dizendo que ele é autista (...). Por mais que rotule, eu acho que protege mais. (...). A mesma coisa [ocorre quando] você para numa vaga especial (...), o que (...) esse moleque tem? Esse moleque não tem nada, ele corre, ele anda. Eles acham que necessidade é só física”. Este relato da mãe de Leonardo revela circunstância ou situação em que o autista pode ser considerado como adolescente igual a outro adolescente por sua condição física ou por sua vestimenta. A igualdade determinaria que a criança autista pudesse, por terceiros, ser chamada de "moleque" ou ser considerada como sendo "normal", como qualquer outra criança. O relato da mãe de Leonardo deixa ainda claro que o autista é visto como um problema quando a "molequice" e a "normalidade" que ele encarna deixam de corresponder ao padrão de comportamento esperado pelo "outro". Esta é a hipótese segundo a qual a igualdade, em cedendo lugar à diferença de comportamento, implica a distinção entre criança autista e criança normal. Ela instaura ainda a desigualdade quanto ao direito de o autista estar ou permanecer em determinados lugares.

Para a mãe de Leonardo, o direito de seu filho estar num determinado lugar e de nele adotar determinado comportamento está associado ao respeito quanto às necessidades de seu filho. Para ela, a condição de realização da relação que articula o de direito um e o respeito pelo outro supõe a identidade de Leonardo como sendo autista. Ao definir "identidade" como sendo a afirmação de um "rótulo", a mãe de Leonardo compreende a identidade do filho como sendo a "etiqueta" que é atribuída ao rotulado por aquele que rotula. A natureza da relação entre aquele que recebe o rótulo e aquele que atribui o rótulo supõe padrão de avaliação e relação de poder que explica que a própria mãe possa vestir o filho com os seguintes dizeres: "sou autista". Se, de um lado, a condição verbal e visualmente afirmada do ser autista expressa a diferença que, aos olhos de terceiros, faz com que ele seja visto ou tratado como um "coitado", por outro lado, ela produz o reconhecimento das necessidades do autista quanto 
a seu comportamento. Neste sentido, o relato da mãe de Leonardo encerra a ambiguidade ou a contradição de todo direito que possui seu fundamento em diferença social e negativamente discriminada. Daí o fato de ela reconhecer que a identidade e o direito do filho envolvem ao mesmo tempo "proteção" e "desproteção".

“[Quando] eu vejo os autistas mais severos (...), eu não sei o que passa na cabeça deles. (...). Mas também têm os autistas com grau mais leve (...). Talvez eles possam ter futuros, pensando em futuros, pensando no que (...) eles querem fazer, eu sinceramente, particularmente, não sei." ${ }^{6}$ Para além da questão do direito que interpela o relato da mãe de Leonardo quanto à identidade particular de autista de seu filho, a fala de Nicolas, de 16 anos de idade, remete o tema da identidade do autista não à distinção de qualidade entre "quem é" e "quem não é" autista, e sim à distinção de grau entre "autistas severos" e "autistas leves". A diferenciação interna quanto à identidade do "autista" que aparece na fala de Nicolas está na base da problematização da própria categoria que é o autismo enquanto condição definida segundo conceito universal. Ao se identificar como autista, Nicolas identifica tipos distintos de autistas que sustentam sua identidade específica quanto a alguém que pode ter futuro, pensar em seu futuro e ter vontade para querer agir. No entanto, como autista, Nicolas reconhece não poder ocupar o lugar de outro autista para falar em seu nome e saber o que ele pensa.

Apesar de afirmar "eu amo ser autista"7 e de não imaginar que o autismo como doença devesse ser curado quanto a tudo aquilo que o caracteriza e o define, Nicolas revela consciência acerca daquilo que o incomoda na sua realidade de autista: "a estereotipia", "o sotaque pausado." ${ }^{8}$ Perguntado sobre a razão da existência dos autistas no mundo, Nicolas como que afirma que a humanidade é constituída de pluralidades distintas e diversas de seres humanos e que os autistas, fazendo parte desta humanidade, comumente vítimas do preconceito alheio, reúnem as mesmas condições que qualquer outro ser humano para estabelecer relações familiares e entre amigos: "Eles estão para mostrar que eles não são nenhum monstro, nenhum retardado. Eles têm a condição de viver nesse planeta e que eles têm condição de também ter uma família, amigos e não podem também ser tratados como lixo, como as pessoas preconceituosas fazem."9

\footnotetext{
${ }^{6}$ ALYSSON MUOTRI CONVERSA COM O JOVEM AUTISTA NICOLAS BRITO SALES. G1. Disponível em: 〈http://g1.globo.com/videos/v/alysson-muotri-conversa-com-o-jovem-autista-nicolas-brito-sales/4573372/〉. Acesso em: 03 mar. 2019, 13:44:00.

7 Ibidem.

8 Ibidem.

${ }^{9}$ Ibidem.
} 
Esta é a fala direta de um autista com seu interlocutor sobre autistas. Nicolas se comunica oralmente por si só, mas nem sempre foi assim. "[Antes de eu me comunicar pela fala], eu só mexia a cabeça. E já era suficiente". ${ }^{10}$ No contexto dos relatos de Nicolas, a comunicação - ainda que apenas gestual - é condição suficiente - e assim necessária - para que o autista exista e seja reconhecido como ser humano. Esta relação que articula "comunicação" e "pessoa humana" - ou a definição do sujeito pela comunicação - é afirmada de forma expressa - e às avessas - na seguinte fala de Susan Rubin, de 26 anos: "Quando eu não era capaz de me comunicar, na verdade, eu era uma não-pessoa". ${ }^{11}$ Assim como Nicolas, nem sempre Susan pôde comunicar-se. "Todos os meus movimentos eram muito esquisitos e todos os meus sons sem sentido me faziam parecer retardada. (...) Isto foi assim até eu ter um sistema de comunicação que me permitiu comunicar a partir dos sons." 12 Nesta sua afirmação, Susan revela a distinção de dois momentos em sua vida referidos a dimensões de sua identidade que expressam a oposição entre "pessoa" e "não-pessoa" segundo o critério "comunicação". Quando não se comunicava, Susan era considerada como sendo "retardada". ${ }^{13}$ A comunicação como fato mediatizado pelo uso de aparelho é considerada por Susan como condição do despertar de sua consciência e de sua emergência como pessoa humana. Daí Susan não se surpreender com o fato - que ela não qualifica como sendo expressão de preconceito - de parecer ser "retardada" por não se comunicar com as demais pessoas e como as demais pessoas.

Por outro lado, a despeito da ausência da capacidade de comunicação, o "retardamento" pode ser associado à presença daquilo que nem mesmo o autista é capaz de explicar de forma satisfatória: "Eu contribuo conscientemente para a minha aparência retardada ao carregar para todos os lados uma colher de plástico. Mas colheres são o meu conforto. Eu não consigo explicar como ou porque eu preciso delas, eu simplesmente preciso delas." ${ }^{14}$ A despeito da consciência de sua trajetória e da capacidade de falar de sua identidade de autista segundo a ideia de que "comunicação" define "pessoa", Susan não deixa de reconhecer que o autista - ainda que considerado como pessoa - pode ser definido também - e

\footnotetext{
${ }^{10}$ AUTISM Is a World. Direção: Gerardine Wurzburg. Produção: Gerardine Wurzburg. Estados Unidos das América (EUA).

${ }^{11}$ AUTISM Is a World. Direção: Gerardine Wurzburg. Produção: Gerardine Wurzburg. Estados Unidos das América (EUA).

${ }^{12}$ Ibidem.

${ }^{13}$ Ibidem.

${ }^{14}$ Ibidem.
} 
ao mesmo tempo - segundo o critério de normalidade: "Eu amo ir para a pista de corrida [de cavalos], pois é um lugar onde eu posso me misturar com a multidão e parecer normal. Todo mundo está olhando para os cavalos, e não para mim." ${ }^{15}$ No entanto, a normalidade - como desejo, necessidade ou sentimento de Susan - importa a invisibilidade do autista. Na multidão, Susan desaparece como austista, mas não apenas ela. Na multidão, todas as demais pessoas também desaparecem, segundo o entendimento de Susan. Para ela, a normalidade está associada ao desaparecimento que invisibiliza e iguala as pessoas ao mesmo tempo. Afinal, "todo o mundo está olhando para os cavalos". ${ }^{16}$ Para ela, o oposto da multidão pode ser a sala de aula: "O autismo é uma luta constante. Ele toma cada gota de energia que eu tenho para sentar um tanto quieta durante uma aula de duas horas." ${ }^{\prime 17}$ A oposição entre o prazer de parecer normal na multidão que se encontra nos espaços abertos de uma corrida de cavalos e o desprazer pelo dispêndio real de energia para manter-se calma nos limites de uma sala de aula durante um certo tempo expressa tanto os espaços de socialização e convivência de Susan como os elementos que compõem e definem sua identidade.

Apesar do autoreconhecimento como sendo "não-pessoa" em seu passado, pela incapacidade de comunicação - e de até mesmo compreender possa ainda ser considerada como sendo "retardada", a despeito de sua capacidade de comunicar-se -, Susan afirma que há elementos da identidade do autista que não são conhecidos em razão da ausência de comunicação adequada: "Odeio muito o fato de que pessoas não-verbais com autismo não tenham oportunidade de mostrar a sua inteligência." 18 Assim, para Susan, a inteligência, comunicada ou não, também define o autista. O sentimento de ódio que Susan expressa talvez possa ser explicado pelo fato de que a inteligência não comunicada - e assim ignorada - possa contribuir para que o autista permaneça aprisionado à incapacidade de comunicação daquilo que é próprio do ser humano e que assim seja definido ou percebido como sendo "não-pessoa".

A passagem da condição de "não-pessoa" para a de "pessoa", como expressão da superação da incapacidade absoluta de comunicação - e assim da afirmação da liberdade que define o ser humano -, parece não ser idealizada por Susan enquanto processo ou fato que corresponda à realidade de fato dos autistas: "Por mais independente que eu possa ter me tornado, o fato triste é que eu sempre precisarei de outros para me comunicar. E emoções são

\footnotetext{
${ }^{15}$ Ibidem.

${ }^{16}$ Ibidem.

${ }^{17}$ AUTISM Is a World. Direção: Gerardine Wurzburg. Produção: Gerardine Wurzburg. Estados Unidos das América (EUA).

${ }^{18}$ Ibidem
} 
as mais difíceis de falar a respeito."19 Assim, livre e independente porque capaz de afirmar sua inteligência, Susan considera-se presa e dependente de terceiros porque incapaz de falar sobre suas emoções. No entanto, essa dependência diz respeito também à vida no seu quotidiano rotineiro: "Eu preciso de uma ajudante comigo 24 horas por dia para me ajudar com a vida no dia-a-dia. Limpar a casa, fazer compras, estudar e visitar a família. (...). Eu não conseguiria ligar para o 911 se eu estivesse em apuros. ${ }^{, 20}$ Embora afirme positivamente estar incluída social e intelectualmente, cultural e pessoalmente, e reconheça a excelência de sua família e da escola no seu processo de interação com o mundo a seu redor, Susan revela visão negativa acerca da relação que articula "autismo" e "autista": "Nunca se estará livre do autismo. As tendências de ser e de agir de certas formas diminuem, mas eu sempre serei autista." ${ }^{21}$ Para Susan, é como se o autismo aprisionasse o autista em sua identidade, é como se o autista não pudesse liberta-se do autismo que o constitui.

A "realidade" dos autistas através dos relatos traz não apenas a crítica a uma suposta "identidade" propriamente "autista" ou do "autista", mas principalmente à concepção de sujeito ou ser humano que não considera a diversidade de formas e a pluralidade de modos que definem a condição que constitui a pessoa humana no mundo de suas interações e comunicações. A descrição do mundo das interações e comunicações reais dos autistas através de narrativas individualizadas garante perspectivação teórica do sujeito ou do ser humano com base não na abstração, e sim na afirmação da complexidade que caracteriza a organização pessoal não apenas dos autistas, mas como de qualquer outra pessoa, como resultante das formas, dos modos e dos limites de suas interações com o mundo. Assim, o mundo dos autistas questiona "identidade" e "sujeito" enquanto categorias tanto práticas quanto teóricas que "aprisionam" e "libertam" o ser humano segundo variáveis tão distintas quão diversas. Se esta é a condição fundamental de uma "teoria geral do sujeito", ela vem expressa na linguagem da "normalidade" usada no mundo dos autistas e associada aos sistemas médico, jurídico e social.

\section{IDENTIDADE, SUJEITO E SISTEMA JURÍDICO}

\footnotetext{
${ }^{19}$ Ibidem.

${ }^{20}$ Ibidem.

${ }^{21}$ AUTISM Is a World. Direção: Gerardine Wurzburg. Produção: Gerardine Wurzburg. Estados Unidos das América (EUA).
} 
Três vias jurídicas definem a pessoa com autismo no direito brasileiro: a via da capacidade civil, a via dos diplomas genéricos e a via dos diplomas específicos.

Com espectro que abarca pessoas com maior ou menor grau de "performance" social, linguística e cognitiva, os institutos que relativizam a capacidade civil devem ser analisados pontualmente, em cada caso específico. Afinal, não é possível a inferência de qualquer forma de relativização da capacidade civil simplesmente pelo diagnóstico de autismo. A condição per se de autista não relativiza a capacidade da pessoa autista. Deste modo, a pessoa com autismo é presumida capaz por imperativo do artigo $1^{\circ}$ do Código Civil, ${ }^{22}$ desde que maior de 18 anos. Por outro lado, ela pode ser considerada relativa ou absolutamente incapaz, caso haja enquadramento em uma das hipóteses dos artigos $3^{\circ}$ e $4^{\circ}$ do Código Civil.

A sistemática da capacidade civil foi recentemente alterada pelo Estatuto da Pessoa com Deficiência (Lei 13.146/2015). ${ }^{23}$ Ele aboliu a incapacidade absoluta de pessoas maiores de 16 anos e manteve a relativa capacidade somente em casos de "ébrios habituais e viciados em tóxico", "pródigos" ou daqueles que "[...] não puderem exprimir sua vontade". Desse modo, a pessoa adulta (maior de 18 anos) com autismo terá a sua capacidade relativizada somente se não puder exprimir a sua vontade (ou for ébria habitual, viciada em tóxico ou pródiga). Trata-se de evolução normativa, no sentido de melhoria e avanço, que tende a diminuir a restrição de direitos das pessoas que se encontrem no espectro.

De forma específica, a lei 12.764/2012 instituiu a "Política Nacional de Proteção dos Direitos da Pessoa com Transtorno do Espectro Autista". ${ }^{24}$ Este é o mais importante diploma legal brasileiro que versa sobre direitos da pessoa com autismo. Ainda que reforce uma série de direitos com fundamento em outras normas (e até mesmo da Constituição), a lei Berenice Piana apazigua discussões antigas com o segundo parágrafo de seu primeiro artigo: "§ $2^{\circ}-\mathrm{A}$ pessoa com transtorno do espectro autista é considerada pessoa com deficiência, para todos os

\footnotetext{
${ }^{22}$ BRASIL. Código Civil. Lei n. ${ }^{\circ} 10.406$ de 10 de janeiro de 2002. Congresso Nacional, Brasília, 2002. In: Diário Oficial da União de 11 de janeiro de 2002. Disponível em: <http://www.planalto.gov.br/ccivil_03/leis/2002/110406.htm> Acesso em: 03 mar. 2019, 16:15:00.

${ }^{23}$ BRASIL. Lei n. ${ }^{\circ} 13.146$ de 06 de julho de 2015. Congresso Nacional, Brasília, 2015. In: Diário Oficial da União de 07 de julho de 2015. Disponível em: <http://www.planalto.gov.br/ccivil_03/_Ato20152018/2015/Lei/L13146.htm> Acesso em: 03 mar. 2019, 16:15:00.

${ }^{24}$ BRASIL. Lei n. ${ }^{\circ} 17.764$ de 27 de dezembro de 2012. Congresso Nacional, Brasília, 2012. In: Diário Oficial da União de 28 de dezembro de 2012. Disponível em: < http://www.planalto.gov.br/ccivil_03/_ato20112014/2012/lei/112764.htm> Acesso em: 03 mar. 2019, 16:15:00.
} 
efeitos legais. ${ }^{, 25}$ Este parágrafo relaciona toda pessoa que se encontre no espectro autista com as leis voltadas para a pessoa com deficiência. O direito brasileiro define, portanto, a pessoa com autismo como pessoa com deficiência para todos os fins legais.

\section{PARA PENSAR “SUJEITO”, "PESSOA" E "INDIVÍDUO” (1)}

"No sistema [social] brasileiro, é básica a distinção entre o indivíduo e a pessoa como duas formas de conceber o universo social e de nele agir" (DAMATTA, 1990, p. 178179). Para o autor de Carnavais, Malandros e Heróis, preocupado com a definição da identidade social do brasileiro, o indivíduo e a pessoa correspondem a diferentes níveis de operação do sistema social. O primeiro atua por meio de leis globais, no contexto de situações impessoais, universalizantes e igualitárias; o segundo, por meio de particularizações, no contexto de situações pessoais, concretas e diferenciadoras. O indivíduo é considerado como sendo livre e igual a todos, como tendo escolhas e fazendo as regras; a pessoa, como sendo presa à totalidade social e complementar aos outros, como não tendo escolhas e recebendo as regras.

A preocupação com a identificação dos sujeitos caracteriza também o pensamento do autor de Quando Novos Personagens Entram em Cena: "Poucas noções são tão ambíguas, carregadas de sutilezas e mal-entendidos como essa [a noção de sujeito]. Se num enunciado ela pressupõe a soberania do ator, num outro pressupõe sua sujeição" (SADER, 1988, p. 50). O sujeito que define os movimentos sociais que interessam ao autor são os personagens que vivem as experiências da condição proletária na Grande São Paulo entre os anos de 1970 e 1980. “Quando uso a noção de sujeito coletivo é no sentido de uma coletividade onde se elabora uma identidade e se organizam práticas através das quais seus membros pretendem defender seus interesses e expressar suas vontades, constituindo-se nessas lutas" (SADER, 1988, p. 55). A preocupação teórica de Sader com a definição do conceito "sujeito" em sua relação com as experiências e lutas dos trabalhadores conduz o autor à adoção de perspectiva e prática metodológicas fundamentadas na teoria e na prática da Análise de Discurso. "Os diversos discursos que lemos ou escutamos numa sociedade num dado período (...) podem ser remetidos a matrizes discursivas que compõem (...) um modo (...) de nomear seus problemas,

${ }^{25}$ Ibidem.

Revista Brasileira de Filosofia do Direito | e-ISSN: 2526-012X | Belém | v. 5 | n. 2 | p. 21 - 42 | Jul/Dez. 2019. 
objetivos, valores" (SADER, 1988, p. 59). Faz parte deste rol de nomeação, a constituição da identidade dos sujeitos. Assim, os discursos desempenham o papel de constituição dos sujeitos no mundo tanto da vida como da teoria.

"A direção consciente pelos próprios homens de suas vidas" (CASTORIADIS, 1979, p. 107) define a ideia de "autonomia" que está na base do pensamento do autor de $O$ Conteúdo do Socialismo e define de modo essencial o ser humano. A autonomia que define o homem é concebida de forma independente da dicotomia clássica que opõe sociedade e indivíduo. "Para começar e de forma essencial, o indivíduo não é nada mais do que a sociedade" (CASTORIADIS, 1990, p. 52). No entanto, ela supõe a atribuição de uma dimensão prática à reflexão e ao pensamento, o que explica a adesão do autor ao marxismo. Por outro lado, “[...] esta atividade do sujeito que 'trabalha sobre si mesmo' encontra como seu objeto a multidão de conteúdos (o discurso do Outro) com o qual ela nunca terminou de se haver; e sem esse objeto ela simplesmente não é" (CASTORIADIS, 1982, p. 127). Assim, dando a si próprio o objeto que constitui a condição de sua existência, o sujeito autônomo não é concebido senão como resultante das determinações que lhe são externas.

"A grande criação cultural, artística ou filosófica, ainda que seja ligada a movimentos coletivos, realiza-se plenamente através de personalidades individuais" (COUTINHO, 2006, p. 109). Embora reconheça que o sujeito individual possa expressar concepção de mundo coletiva no campo filosófico ou artístico, o autor de Intervenções afirma que "a presença do sujeito coletivo, na política, é muito mais forte do que na criação artística ou filosófica: é até mesmo decisiva. Lenin é Lenin porque foi dirigente do Partido Bolchevique". Crítico do pensamento de Lukács, que ele afirma atribuir caráter excessivamente individual ao sujeito político, o autor de Marxismo e Política sentencia: "É como se a práxis política criadora (...) fosse também ela (...) a expressão de personalidades excepcionais e não de sujeitos coletivos" (COUTINHO, 1994, p. 156). Considerando que da transformação radical da sociedade há outros atores políticos além daqueles que são centrais no mundo do trabalho, o autor de Intervenções afirma: "Devem articular suas demandas particulares com as demandas universais do socialismo e da transformação social" (COUTINHO, 2006, p. 131). Tomando parte do "novo sujeito revolucionário", e dentro de uma estratégia universalista, eles atores políticos são os movimentos sociais das mulheres, dos homossexuais, das minorias raciais. 
"Eu não sou dona de minha vida, decidi oferecê-la a uma causa. (...). O mundo onde vivo é tão criminoso, tão sanguinário, que de um momento para o outro me tira. Por isso, como única alternativa, só me resta a luta. (...). Somente as massas são capazes de transformar a sociedade. E não é mera teoria apenas" (DUSSEL, 2002, p. 416). Esta citação traduz a preocupação de seu autor com um novo critério de validade discursiva no âmbito de sua Ética da Libertação - a validade crítica da razão libertadora - e com a fecundidade do desenvolvimento de seu método histórico - de acordo com o qual a "experiência" latinoamericana é essencialmente original. $\mathrm{O}$ autor de Ética da Libertação concebe como ponto de partida de seu pensamento "as vítimas da não-comunicação" (DUSSEL, 2002, p. 418). Elas são os excluídos da própria comunidade de comunicação. Ao dar a palavra à própria vítima (Rigoberta Menchú) (ou ao escutá-la?) em sua Ética da Libertação, o autor procura fazer valer o princípio concreto “"Faze participar na discussão o afetado-excluído, a vítima!'” (DUSSEL, 2002, p. 418). Do ponto de vista metodológico, a exposição que testemunha a experiência de Rigoberta Menchú constitui o ponto de partida na elaboração do estatuto teórico do "outro" como vítima, como negado-oprimido, como afetado-excluído, e não como "outro" enquanto outra pessoal-igual na comunidade argumentativa, tal como entende a tradição da Ética do Discurso.

“O que há de único é o que é partilhado (DUBAR, 2009, p. 13). Esta é a perspectiva adotada pelo autor de A Crise das Identidades. Seu desenvolvimento - que supõe que identidade é diferença e também pertencimento comum - produz paradoxo que não pode ser solucionado. Este fato pode ser explicado pela presença do elemento comum que caracteriza a diferenciação e a generalização: a identificação do outro e pelo outro. Isto significa dizer que não há identidade sem alteridade. Por outro lado, como alteridade, toda identidade varia historicamente e depende de seu contexto social de definição. Dubar é crítico quanto à pretensão da sociologia de compreender processos de construção e mudanças da identidade pessoal dos indivíduos. "Ela deve analisar sociologicamente o uso que as pessoas fazem de suas próprias categorias, sua maneira específica de escolher e dispor das palavras vindas de suas experiências, tanto por meio de suas interações cotidianas 'presentes' como das lembranças de suas interações 'passadas' apropriadas por meio de sua reflexão pessoal (DUBAR, 2009, p. 240). 


\section{PARA PENSAR "SUJEITO”, "PESSOA" E "INDIVÍDUO” (2)}

Ocupar-se do sujeito pressupõe assumir a tarefa de ocupar-se, também, das ideias de "pessoa" e de "indivíduo", inseridas ou não no contexto do humano. Hobbes apresenta o conceito de pessoa com seu significado mais afim às ciências políticas e jurídicas: "uma pessoa é o mesmo que um ator, tanto no palco como na conversação corrente. E personificar é representar, seja a si mesmo ou a outro; e daquele que representa outro diz-se que é portador de sua pessoa, ou que age em seu nome (HOBBES, 1999, p. 135). Pessoa, portanto, é máscara, é ator. Pessoa é tema filosófico, mas é principalmente teológico e jurídico. Apesar de sua origem latina (persona) e da atuação no teatro grego (prósopon), a teologia cristã tivera participação fundamental para a construção da definição que fora herdada pelo pensamento ocidental, ao tentar responder à seguinte questão: como poderia ser Cristo humano e divino? No Concílio de Nicéia, de 325: "Cristo tem uma dupla natureza - a divina e a humana -, mas tem só uma pessoa, que é única e indivisível. A ideia de pessoa podia, assim, religar em Cristo o humano e o divino, ao mesmo tempo que distinguir entre eles (MORA, 2001, p. 2262). A apropriação da ideia de pessoa pela teologia cristã pavimentou o caminho para a filosofia moderna estabelecer um conceito que terminou por unir o indivíduo e o humano, e que se articulará enquanto o eixo que fundamentará, posteriormente, o cogito cartesiano: a razão. Ainda que a relação entre existência e racionalidade esteja explícita em Descartes, em Boécio já se identificava a máxima “a pessoa é uma substância individual de natureza racional" (MORA, 2001, p. 2263).

Desde ao menos a escolástica, portanto, a pessoa era compreendida como o indivíduo racional. Para Leibniz, “a palavra 'pessoa' comporta a ideia de um ser pensante e inteligente, capaz de razão e de reflexão, que pode considerar-se a si mesmo como o mesmo, como a mesma coisa, que pensa em diferentes tempos e em diferentes lugares, o que faz unicamente por meio do sentimento que possui de suas próprias ações” (MORA, 2001, p. 2264, grifo nosso). Ainda na modernidade, é possível extrair conceituação de "personalidade" que, como em Leibniz, imprescinde do racional: "a pessoa, que pertence ao mundo sensível, está sujeita à sua própria personalidade, contanto que ela pertença ao mundo inteligível (KANT, 1974, p. 155, tradução nossa). Em Kant, portanto, a liberdade se apresenta na faculdade de a pessoa submeter-se a leis próprias, advindas de sua própria razão. Deste modo, a racionalidade não é 
somente condição da personalidade, mas é somente através dela que uma pessoa pode alcançar a liberdade.

A aproximação com o pensamento contemporâneo garante notar tendência à distinção entre "indivíduo" e "pessoa”. "O termo 'indivíduo' se aplica a uma entidade cuja unidade, embora complexa, é definível negativamente: algo, ou alguém, é indivíduo quando não é outro indivíduo" (MORA, 2001, p. 2264). Não se cogita aqui o fundamento racional ou, sequer, um vínculo humano. Neste afastamento entre os conceitos, “o termo 'pessoa' se aplica a uma entidade cuja unidade é definível positivamente e, além disso, com 'elementos' procedentes de si mesma. [...] O indivíduo é determinado em seu ser; a pessoa é livre e ainda consiste em ser tal" (MORA, 2001, p. 2264). Seguindo as transformações da ideia de pessoa no pensamento ocidental, Ferrater Mora conclui que, "com respeito à estrutura, tendeu-se a abandonar a concepção 'substancialista' da pessoa para fazer dela um centro dinâmico de atos. Quanto a suas atividades, tendeu-se a contar entre elas as volitivas e as emocionais, tanto ou mais que as racionais" (MORA, 2001, p. 2264). Aproxima-se, aqui, da ideia de um "autor" de uma ação - conceito que a ciência jurídica e legislações modernas têm adotado. Destarte, a pessoa age por vontade e responde por seus atos. O direito, entretanto, afasta-se pouco do eixo racional marcado pela história da "pessoa" até o modernismo: a incapacidade de compreensão no agir repercute diretamente sobre a responsabilização pelos atos cometidos. O afastamento da responsabilidade por aquele que não "goza(ria) do pleno uso de suas faculdades mentais" é antigo.

Perquirindo investigação de viés filosófico, a abordagem neste momento do conceito de "sujeito" supõe tarefa "perigosa". A miscelânea de aplicações - algumas mais específicas, como na gramática ou na lógica; algumas menos, como no pensamento de alguns juristas transforma a utilização do termo em verdadeiro desafio. A confusão entre sujeito, pessoa, indivíduo e humano/homem é corriqueira na academia jurídica. Lalande, ao expor o conceito jurídico de sujeito, cita Colin e Capitant: “As pessoas ou seres humanos são sujeitos do Direito... A palavra pessoa (de persona, máscara do ator antigo) exprime bastante bem a ideia de que os sujeitos do Direito não são homens totais, mas homens considerados como atores da vida social sob uma certa relação; numa palavra, abstrações” (LALANDE' 1999, p. 1090). Aqui, pessoa é confundida com ser humano, que é confundido com sujeito - mas é um homem não total. Cada jurista busca compreender de forma própria as distinções entre sujeito e pessoa, entre sujeito e indivíduo. A tentativa de destrinchar o que se precisa com cada uma dessas palavras não é recente e encontra mesmo na Teoria Pura de Hans Kelsen seção 
específica: "define-se o conceito de pessoa como "portador" de direitos e deveres jurídicos, podendo funcionar como portador de tais direitos e deveres não só o indivíduo mas também estas outras entidades" (KELSEN, 1998, p. 191).

Neste esboço investigativo, que, a partir de referências ao pensamento de Hobbes, salta da Roma e da Grécia antigas à escolástica, e que freia na modernidade, o direito se insere como rincão do saber, no qual a pessoa, o indivíduo e o sujeito apresentam basilar importância. Aqui o direito repete o modo de funcionamento que lhe é particular: toda absorção de conhecimento significa apropriação. No direito, o sujeito racional, capaz de agir segundo sua própria vontade, continua como categoria fundamental do empírico e do abstrato. Por certo que teorias críticas surgem e procuram desestabilizar a hegemonia humana do espaço da personalidade, mas o sujeito continua monoliticamente dominante. O que se encarou pouco - e certamente ainda não se absorveu - é o fato de que o sujeito está em crise há pelo menos um século. Das elucubrações nietzscheanas e psicanalíticas à tradição francesa da segunda metade do século XX, o sujeito tem sido questionado e dilacerado. Ainda hoje são empenhados esforços para a desconstrução e o afastamento deste "espectro" (ŽIZEK, 2016). Pensar o "ser humano" como um ser universal e o indivíduo como unidade são alvos certeiros de críticas psicanalíticas, antropológicas e sociológicas. Entretanto, a atenção e a valorização no e pelo direito desses conceitos enquanto categorias próprias e sólidas continuam em vigor, com um modus operandi de alargamento do sujeito (e da pessoa, e do indivíduo, e do "ser humano"), adicionando outras categorias a esses topoi como forma legítima e, talvez, única de expansão de direitos (se o sujeito e a pessoa são os lugares dos direitos "humanos", a ampliação do que seja sujeito e pessoa seria uma prática solução: a natureza, por exemplo, passa a ser sujeito de direito). Aqui, compreende-se a suspensão, pelos juristas, dentro da tradição moderna, em uma tentativa de apresentação da pessoa e do sujeito enquanto indivíduos racionais.

\section{A RELAÇÃO ENTRE "SUJEITO", "PESSOA" E "INDIVÍDUO"}

Do ponto de vista médico, o autismo é uma questão de "diagnóstico" e está referido à definição do grau de indiferença e de habilidade do autista, isto é, à demarcação do espectro do autismo quanto à vida social, à capacidade cognitiva e ao ato comunicacional. Estes são 
critérios que definem os tipos de autista - questão de grau - e que distinguem os autistas dos não-autistas - questão de qualidade. Do ponto de vista jurídico, supondo transtorno e deficiência da pessoa, ele é uma questão de "regulação" e diz respeito à capacidade de o autista produzir atos jurídicos válidos na vida civil, isto é, ser maior de dezesseis anos e capaz de expressar a sua vontade. Estes são critérios que equiparam autistas e não-autistas. Assim, o diagnóstico de autismo não elimina de forma necessária a capacidade civil do autista. Diagnosticado como autista, João responde juridicamente por seus atos de natureza cível como qualquer outra pessoa. Como pessoa com a qualidade de "autista", João é também "pessoa" sem predicado. Neste sentido, revelando através de suas palavras e ações pertencimento ao mundo sensível e ao mundo inteligível, João pode ser considerado pessoa no sentido kantiano do conceito. Afinal, sua liberdade de contratar está subordinada à própria razão que orienta seu modo de proceder de acordo com as leis vigentes. Como direito que implica deveres e que está referido ao "homem", a liberdade de contratar define João como pessoa no sentido kelseniano da expressão. No entanto, sendo possível o uso do conceito "pessoa" para definir "entidades" tais como estados e municípios, a categoria teórica kelseniana possui como referência categorias práticas que distinguem entre humanos e nãohumanos. Como indivíduo, na história do conceito exposta por Ferrater Mora, João não seria sequer considerado "pessoa". Nem mesmo a condição de "homem não total" em Colin e Capitant seria capaz de descrevê-lo. Assim, no direito e perante o direito (conhecimeto e legislação), João é o autor de suas ações e por elas responde de acordo com o direito.

Assim considerado e assim agindo no mundo, João pode ser definido como “indivíduo", livre e igual a outras pessoas, que, com mais de dezesseis anos de idade, são capazes de contratar de forma válida, desde que atendam à exigência jurídica da "representação legal". No entanto, ele não seria indivíduo no sentido conferido à expressão por DaMatta. Para o antropólogo, o indivíduo - situado no espaço social da "rua" e do mercado - se constitui em relação dialética com a pessoa - situada no espaço social da "casa" e da família, e a constituição dialética do indivíduo implica a passagem de um nível (o da pessoa na casa) para outro (o do invíduo na rua) e é caracterizada pelo "trauma" quanto a esta passagem. A dialética não caracteriza a experiência vivida por João, que tem acesso ao mundo da "rua" e do "mercado" de forma mediatizada pelo uso das tecnologias que domina, sem sair de casa. Se indivíduo em outro sentido, João não se constitui como pessoa no sentido definido por DaMatta. A vigilância, o controle e a intervenção da mãe nas compras do filho não 
revelam o caráter complementar que caracteriza a pessoa na sociologia de DaMatta. A ausência da relação dialética entre indíviduo e pessoa caracteriza também a relação de Susan com terceiros e familiares. Enquanto indivíduo capaz de expressar sua vontade e de comunicar sua inteligência, Susan depende de terceiros para viver sua vida cotidiana quanto a tarefas domésticas consideradas básicas. A dependência de Susan em relação à família não a constitui como pessoa complementar aos outros.

Por outro lado, tanto Nicolas como Susan revelam a capacidade de identificar e falar de seus problemas e objetivos, de seus valores e sentimentos. No sentido em que Sader concebe o "operário" como sujeito coletivo, isto é, como sujeito de luta cuja identidade é definida por seu discurso quanto a seus problemas, objetivos e valores, é possível reconhecer que Nicolas e Susan - com abstração da dimensão política que caracteriza o sujeito coletivo de Sader - se constituem como sujeitos de seus discursos e através de seus discursos. Passando pela condição de "autista" e indo além dela, eles fazem afirmações que representam e constituem práticas em suas vidas cotidianas que eles próprios vivenciam como sendo expressão de "dificuldades e lutas", ainda que não políticas, por reconhecimento de seus interesses, desejos, necessidades. João afirmou querer "fechar uma compra", Nicolas afirmou querer "ter uma família e fazer amigos", Susan afirmou "ser dependente de terceiros e da família" no cotidiano. Segundo a definição hobbesiana de pessoa no campo tanto jurídico quanto político - sujeito cujas palavras e/ou ações lhe são próprias (pessoa natural) ou pertencem a terceiros (pessoa fictícia) -, João, Nicolas e Susan podem ser considerados como pessoas. Afinal, através de suas próprias palavras ou ações, eles representam a si mesmos.

No sentido do pensamento de Castoriadis, estas afirmações permitem pensar a medida em que João, Nicolas e Susan se constituem como sujeitos autônomos, não por serem inteligentes ou capazes de pensar, e sim por "trabalharem sobre eles mesmos". O trabalho que eles realizam implica relação com os discursos de outros sujeitos com os quais eles se relacionam, isto é, com "uma multidão de conteúdos", que opera como objeto que os constituem como sujeitos e que definem a sua existência. A despeito das formas práticas de discriminação que sofrem ("retardado", "doente mental", "anormal", “doido") e dos modos pelos quais eles próprios se vêem em algum momento de suas vidas ("eu estou presa ao autismo", "eu sou uma não-pessoa", "eu gostaria de tirar meu sotaque pausado"), João, Nicolas e Susan provável ou certamente não podem ser considerados sujeitos autônomos segundo a hipótese definida por Dussel, para quem os sujeitos se constituem através de 
discursos pelos quais eles se reconhecem como excluídos e vítimas de determinado "sistema". Afinal, eles não são "vítimas da não-comunicação". A exposição dos relatos que testemunham a experiência pessoal e íntima de João, Nicolas e Susan mais parece estar referida à "multidão de conteúdos" de que trata Castoriadis. Como discriminados e auto-discriminados, eles mais parecem se aproximar do "Nós" deste autor do que do "Outro" de Dussel. Eles mais parecem negar a condição de vítima, como negado-oprimido, e afirmar a condição de "outro", como outra pessoa-igual no campo discursivo, como pessoa enquanto indivíduo racional. Neste trabalho, os relatos dos autistas ou sobre os autistas quanto a o que eles são, bem como o modo como eles são definidos ou classificados pelos sistemas médico e jurídico, mais parecem definir o problema da identidade - e de seus critérios - segundo o que Dubar chamou de "identificação contingente". Sendo também plural e concomitante, concorrente e colidente, a identificação revela o caráter problemático da identidade como expressão de verdadeiro paradoxo.

A capacidade que define João como sujeito jurídico responsável está na origem do temor de sua mãe. João é indivíduo livre para contratar, mas vive sob a vigilância e o controle da família. Por sua condição física, o autista pode ser considerado em "meio ambiente" determinado como adolescente igual a outro adolescente e ser ao mesmo tempo distinguindo entre os adolescentes quanto à diferença de seu comportamento. Assim, o autista é considerando como sendo igual e diferente ao mesmo tempo. Nicolas afirma que o autista é um ser humano igual a todo ser humano e faz parte da humanidade, mas ele também reconhece a existência da variação interna dentro da categoria "autista". Do ponto de vista de sua história, Susan reconhece momentos em que se via como pessoa e não-pessoa, segundo sua capacidade de comunicação. Por outro lado, ao se sentir normal como todo o mundo quando em "relação" com outras pessoas - tal como numa pista de corrida de cavalos -, Susan percebe negativamente que esta situação cancela sua condição de autista. Se não há identidade sem alteridade, não há também identidade sem "subjetividade", construída como resultante da relação que articula o "dentro" e o "fora", o "eu" e o "outro", o "passado" e o "presente". A visão do "outro" sobre o autista está em relação com a visão do "eu" do autista sobre ele mesmo. Embora se considere um ser livre para se comunicar enquanto autista, Susan afirma também que nunca estará livre do autismo. Neste sentido, a crítica de Dubar às pretensões sociológicas não seria amparada pela argumentação mais filosófica de Castoriadis. Por outro lado, se a capacidade de razão e de reflexão de Susan ocorre por meio de 
sentimentos que ela revela, Susan não se percebe como a mesma pessoa em diferentes tempos e lugares, condição da definição da categoria "pessoa" em Leibniz.

\section{CONCLUSÃO}

Neste trabalho, o campo das relações dos autistas, o campo dos diagnósticos dos médicos, o campo das normas dos legisladores e o campo das definições de teóricos e filósofos foram abordados enquanto "fenomenologias" distintas e diversas que operam com sistemas classificatórios próprios na compreensão e definição do sujeito. É possível afirmar que, em seu isolamento, nenhuma das referidas fenomenologias possui condições de produzir metaconceitos ou meta-intepretações capazes de instituir uma "teoria do sujeito" como conhecimento universal com validade inquestionável para o âmbito das demais fenomenologias.

Possuindo por referência tradicional a dimensão técnico-normativa do direito, o sistema teórico-doutrinário do direito ignora as demais instâncias onde o sujeito é pensado e estudado, frequentemente de forma igualmente isolada. Este quadro de negatividade constitui obstáculo à teorização do sujeito no direito. Afinal, é o confronto entre as diversas "fenomenologias" que define condição necessária de problematização e de formulação de teoria do sujeito no direito. Em suas dimensões prática e teórica, referidas a sistemas ou fenomenologias distintas e diversas, a categoria "sujeito" revelou a existência de perspectivas igualmente distintas e diversas. Ela definiu o problema da irredutibilidade do diverso e plural ao geral e universal. Esta conclusão - quanto ao reconhecimento a um só tempo da necessidade e da impossibilidade do universal - constitue "ponto de partida" para se pensar a construção de uma perspectiva que - sem excluir outras perspectivas distintas desta - garanta ao Direito produção coerente e consequente quanto a uma "teoria do sujeito".

A escolha pelo universo do autismo fundamentou-se como lugar de fácil mobilidade para a argumentação sobre o sujeito, lugar esse onde se pôde refletir sobre a pessoa, o indivíduo e o humano. Outras escolhas teriam sido igualmente viáveis, mas o alcance e a riqueza da empiria citada, proporcionados pelos relatos, mereceram o apreço dedicado. Toda relação fundadora e constituinte do sujeito se baseia em uma relação de alteridade, hipótese que fundamenta a problemática jurídica contemporânea. Esta é a conclusão deste trabalho. 


\section{REFERÊNCIAS}

\section{ALYSSON MUOTRI CONVERSA COM O JOVEM AUTISTA NICOLAS BRITO SALES.}

G1. Disponível em: <http://g1.globo.com/videos/v/alysson-muotri-conversa-com-o-jovemautista-nicolas-brito-sales/4573372/>. Acesso em: 03 mar. 2019, 13:44:00.

WURZBURG, Gerardine. AUTISM Is a World. Direção: Produção: Gerardine Wurzburg. Estados Unidos das América (EUA).

BAKER, Jeffrey P. Autism at 70--redrawing the boundaries. The New England journal of medicine, 369, 12, pp. 1089-91, 2013.

BANDEIRA, Gabriela. Autismo não verbal: mães explicam como é comunicação com

filhos adultos. Disponível em: <http://www.portalsingularidades.com.br/2018/02/22/autismonao-verbal/>. Acesso em: 03 mar. 2019, 13:45:00.

BRASIL. Código Civil. Lei n. ${ }^{\circ} 10.406$ de 10 de janeiro de 2002. Congresso Nacional, Brasília, 2002. In: Diário Oficial da União de 11 de janeiro de 2002. Disponível em:

<http://www.planalto.gov.br/ccivil_03/leis/2002/110406.htm> Acesso em: 03 mar. 2019, 16:15:00.

. Lei n. ${ }^{\circ} 17.764$ de 27 de dezembro de 2012. Congresso Nacional, Brasília, 2012. In:

Diário Oficial da União de 28 de dezembro de 2012. Disponível em:

<http://www.planalto.gov.br/ccivil_03/_ato2011-2014/2012/lei/112764.htm> Acesso em: 03 mar. 2019, 16:15:00.

. Lei n. ${ }^{\circ} 13.146$ de 06 de julho de 2015. Congresso Nacional, Brasília, 2015. In:

Diário Oficial da União de 07 de julho de 2015. Disponível em:

<http://www.planalto.gov.br/ccivil_03/_Ato2015-2018/2015/Lei/L13146.htm> Acesso em: 03 mar. 2019, 16:15:00.

CASTORIADIS, Cornelius. A Instituição Imaginária da Sociedade. Rio de Janeiro: Paz e Terra, 1982.

Le Contenu du socialisme. Paris: Union Générale d Édition, 1979.

. Le Monde morcelé; les carrefours du labyrinthe, tome 3. Paris: Seuil, 1990.

Committee on children with disabilities. Developmental surveillance and screening of infants and young children. Disponível em: <http://pediatrics.aappublications.org/content/108/1/192.full>. Acesso em: 03 mar. 2019, 13:48:00. 
COUTINHO, Carlos Nelson. Intervenções; o marxismo na batalha das ideias. São Paulo: Cortez, 2006.

Marxismo e Política; a dualidade de poderes e outros ensaios. São Paulo: Cortez, 1994.

DAMATTA, Roberto. Carnavais, Malandros e Heróis; para uma sociologia do dilema brasileiro. Rio de Janeiro: Editora Guanabara, 1990.

DERRIDA, J.; ROUDINESCO, E. De que amanhã.... Rio de Janeiro: Jorge Zahar Editor, 2004.

DUBAR, Claude. A Crise das Identidades; a interpretação de uma mutação. São Paulo:

USP, 2009.

DUSSEL, Enrique. Ética da Libertação; na idade da globalização e da exclusão. Petrópolis:

Editora Vozes, 2002.

HOBBES, Thomas. Leviatã ou matéria, forma e poder de um estado eclesiástico e civil.

São Paulo: Nova Cultural, 1999.

KANNER, Leo. Autistic disturbances of affective contact. The Nervous Child. 2: 217-50, 1943.

KELSEN, Hans. Teoria Pura do Direito. São Paulo: Martins Fontes, 1998.

LALANDE, André. Vocábulo técnico e crítico da filosofia. São Paulo: Martins Fontes, 1999.

MORA, José Ferrater. Dicionário de filosofia. São Paulo: Edições Loyola, 2001.

SADER, Eder. Quando Novos Personagens Entram em Cena; experiências e lutas dos trabalhadores da Grande São Paulo 1970-1980. Rio de Janeiro: Paz e Terra, 1988.

ŽIZEK, Slavoj. O sujeito incômodo; o centro ausente da ontologia política. São Paulo: Boi Tempo, 2016. 